\title{
Identification and Characterization of Calcium Sparks in Cardiomyocytes Derived from Human Induced Pluripotent Stem Cells
}

\author{
Guang Qin Zhang ${ }^{1,29}$, Heming Wei ${ }^{1,39}$, Jun Lu', Philip Wong ${ }^{1,3}$, Winston Shim ${ }^{1,3 *}$ \\ 1 Research and Development Unit, National Heart Centre Singapore, Singapore, Republic of Singapore, 2 Department of Clinical Pharmacy, China Pharmaceutical \\ University, Nanjing, China, 3 Cardiovascular and Metabolic Disorders Program, DUKE-NUS Graduate Medical School Singapore, Singapore, Republic of Singapore
}

\begin{abstract}
Introduction: $\mathrm{Ca}^{2+}$ spark constitutes the elementary units of cardiac excitation-contraction (E-C) coupling in mature cardiomyocytes. Human induced pluripotent stem cell (hiPSC)-derived cardiomyocytes are known to have electrophysiological properties similar to mature adult cardiomyocytes. However, it is unclear if they share similar calcium handling property. We hypothesized that $\mathrm{Ca}^{2+}$ sparks in human induced pluripotent stem cell (hiPSCs)-derived cardiomyocytes (hiPSC-CMs) may display unique structural and functional properties than mature adult cardiomyocytes.

Methods and results: $\mathrm{Ca}^{2+}$ sparks in hiPSC-CMs were recorded with $\mathrm{Ca}^{2+}$ imaging assay with confocal laser scanning microscopy. Those sparks were stochastic with a tendency of repetitive occurrence at the same site. Nevertheless, the spatial-temporal properties of $\mathrm{Ca}^{2+}$ spark were analogous to that of adult CMs. Inhibition of L-type $\mathrm{Ca}^{2+} \mathrm{Channels} \mathrm{by}^{2}$ nifedipine caused a $61 \%$ reduction in calcium spark frequency without affecting amplitude of those sparks and magnitude of caffeine releasable sarcoplasmic reticulum (SR) $\mathrm{Ca}^{2+}$ content. In contrast, high extracellular $\mathrm{Ca}^{2+}$ and ryanodine increased the frequency, full width at half maximum (FWHM) and full duration at half maximum (FDHM) of spontaneous $\mathrm{Ca}^{2+}$ sparks.

Conclusions: For the first time, spontaneous $\mathrm{Ca}^{2+}$ sparks were detected in hiPSC-CMs. The $\mathrm{Ca}^{2+}$ sparks are predominately triggered by L-type $\mathrm{Ca}^{2+}$ channels mediated $\mathrm{Ca}^{2+}$ influx, which is comparable to sparks detected in adult ventricular myocytes in which cardiac E-C coupling was governed by a $\mathrm{Ca}^{2+}$-induced $\mathrm{Ca}^{2+}$ release $(\mathrm{CICR})$ mechanism. However, focal repetitive sparks originated from the same intracellular organelle could reflect an immature status of the hiPSC-CMs.
\end{abstract}

Citation: Zhang GQ, Wei H, Lu J, Wong P, Shim W (2013) Identification and Characterization of Calcium Sparks in Cardiomyocytes Derived from Human Induced Pluripotent Stem Cells. PLoS ONE 8(2): e55266. doi:10.1371/journal.pone.0055266

Editor: Alexander G. Obukhov, Indiana University School of Medicine, United States of America

Received January 20, 2012; Accepted December 27, 2012; Published February 7, 2013

Copyright: ( $) 2013$ Zhang et al. This is an open-access article distributed under the terms of the Creative Commons Attribution License, which permits unrestricted use, distribution, and reproduction in any medium, provided the original author and source are credited.

Funding: This work is supported by the National Research Foundation of Singapore (NRF2008 NRF-CRP003 002). The funders had no role in study design, data collection and analysis, decision to publish, or preparation of the manuscript.

Competing Interests: The authors have declared that no competing interests exist.

*E-mail: winston.shim.s.n@nhcs.com.sg

9 These authors contributed equally to this work.

\section{Introduction}

Excitation-contraction (E-C) coupling in the adult mammalian heart is governed by the $\mathrm{Ca}^{2+}$-induced $\mathrm{Ca}^{2+}$ release (CICR) mechanism. The process involves entry of $\mathrm{Ca}^{2}$ through L-type $\mathrm{Ca}^{2+}$ channel that activates the ryanodine receptors (RyRs)mediated $\mathrm{Ca}^{2+}$ release from sarcoplasmic reticulum (SR) and resulting in intracellular $\mathrm{Ca}^{2+}$ transients $[1] . \mathrm{Ca}^{2+}$ sparks, a local and transient $\mathrm{Ca}^{2+}$ release originating from a single $\mathrm{RyR}$ or a cluster of RyRs, constitute the elementary events of cardiac E-C coupling [2]. Whole cell $\mathrm{Ca}^{2+}$ transients are believed to represent the recruitment and summation of many $\mathrm{Ca}^{2+}$ sparks after an increase in opened L-type $\mathrm{Ca}^{2+}$ channels [3]. $\mathrm{RyR} \mathrm{Ca}^{2+}$ release channel is tightly linked to the gating of L-type $\mathrm{Ca}^{2+}$ channel and plays a key role in the intracellular $\mathrm{Ca}^{2+}$-handling in cardiac myocytes [4]. Such property of $\mathrm{Ca}^{2+}$ sparks may reflect the organizational maturity of RyRs in the cardiomyocytes [5].

Human induced pluripotent stem cells (hiPSCs) can be generated by somatic reprogramming of fibroblasts with a set of transcription factors and differentiated into multiple cell lineages, including cardiomyocytes [6]. In contrast to human embryonic stem cells (hESCs), hiPSCs are capable of giving rise to a renewable source of cardiomyocytes (CMs) from individuals. These hiPSCderived cardiomyocytes (hiPSC-CMs) offer immensely valuable tool in personalized pharmaceutical evaluation of therapeutic agents such as anti-arrhythmics and provide a tenable means for cardiomyocytes replacement therapy. Therefore, it is important to understand the functional characteristics of such hiPSC-CMs, especially in the cardiac excitation-contraction (E-C) coupling. Whole-cell $\mathrm{Ca}^{2+}$ transients in hiPSC-CMs are dependent on the CICR mechanism in which the key calcium-handling proteins include RyR2, SERCA2a and L-type $\mathrm{Ca}^{2+}$ channels [7,8]. Early studies with mouse ESC-CMs have suggested that developmental stage of cardiac cell differentiation are related to the triggering of $\mathrm{Ca}^{2+}$ sparks and different properties of $\mathrm{Ca}^{2+}$ sparks [9]. However, the characteristics of $\mathrm{Ca}^{2+}$ sparks in hiPSC-CMs remain unclear.

We hypothesized that the $\mathrm{Ca}^{2+}$ sparks in hiPSC-derived cardiomyocytes play instrumental roles in their structural and 
functional maturity. To better understand regulation of $\mathrm{E}-\mathrm{C}$ coupling in hiPSC-CMs, we performed confocal laser scanning microscopy in conjunction with the $\mathrm{Ca}^{2+}$ fluorescent indicator, fluo-4, to determine the relationship between occurrence of spontaneous $\mathrm{Ca}^{2+}$ sparks and activation of L-type $\mathrm{Ca}^{2+}$ channels. The dynamic parameters of $\mathrm{Ca}^{2+}$ spark unveiled novel fundamental characteristics of $\mathrm{Ca}^{2+}$ handling and regulation in hiPSCGMs.

\section{Materials and Methods}

\section{Generation of hiPSC Lines}

Human induced pluripotent stem cells (hiPSCs) were generated in our laboratory from human neonatal dermal fibroblasts (ATCC, USA) via retroviral-based ectopic expression of Yamanaka factors (Oct-4, Sox-2, c-Myc and Klf-4) [6]. The pluripotent status of hiPSCs was confirmed by their expression of pluripotent markers and by their pluripotent differentiation potential including embryoid body (EB) formation and cardiac differentiation in vitro and teratoma formation in vivo. hiPSCs were maintained on mouse embryonic fibroblasts (MEF) feeder in hESC medium $(80 \%$ Knockout Dulbecco's Modified Eagle Medium or DMEM, 20\% Serum replacement, $1 \%$ non-essential amino acid, $1 \mathrm{mM} \mathrm{L-}$ glutamine, $0.1 \mathrm{mM}$ beta-mercaptoethanol and $4 \mathrm{ng} / \mathrm{mL}$ bFGF). Unless specified, all culture reagents were from Invitrogen.

\section{Cardiomyogenic Differentiation of hiPSCs}

Embryoid bodies (EBs) were generated after mechanical dissection of hiPSCs and maintained in suspension culture in a cardiomyogenic medium or CARM which contains DMEM High Glucose $485 \mathrm{~mL}$, L-Glutamine $5 \mathrm{~mL}$, NEAA $5 \mathrm{ml}$, Selenium Transferrin $5 \mathrm{~mL}$ (Sigma) and 2-mercaptoethanol $3.5 \mu \mathrm{L}$ supplemented with $5 \mu \mathrm{M}$ SB 203580 (Sigma), a specific p38MAPK inhibitor [10] in low adherent 6-well plates. Subsequently, EB aggregates were formed and contracting outgrowths emerged from Day 12 onwards. After Day 15, the contracting EB aggregates were plated on $0.1 \%$ gelatin in DMEM containing $2 \%$ FBS. On Day 21, the contracting area of EBs were mechanically dissected out and enzymatically dissociated in Collagenase B (Roche) to small cell clusters containing 15 30 cells according to published protocol with some modifications [11]. Dissociated CMs were continually cultured in DMEM $+2 \%$ FBS for 1 week before testing. All tested hiPSCCMs were kept at the same time point (6-weeks) post the initiation of cardiac differentiation.

\section{Immunocytochemistry}

Detail description of immunocytochemistry assay of hiPSGs is described in Text S1. Briefly, immunocytochemistry assay of hiPSC-CMs was performed with following procedure. Dissociated cultured on glass coverslips were fixed using $4 \%$ paraformaldehyde and permeabilized with $0.1 \%$ Triton-X-100 (Sigma). After blocking with $5 \%$ goat serum in PBS for $1 \mathrm{~h}$ at room temperature, cells stained with mouse anti-human cardiac sarcomeric alphaactinin ( $\alpha$-actinin) (clone EA-35, Sigma) and mouse anti-human cardiac myosin heave chain, beta ( $\beta-\mathrm{MHC}$ ) (Alexis Biochemicals, FL, USA). Next, the primary mAbs was removed and replaced with goat anti-mouse IgG (A11001 Alexa Fluor 488, Invitrogen) for 1 hour. Nuclei were counter stained with DAPI.

\section{Recording of Action Potential}

Dissociated hiPSC-CMs were cultured on $3.5 \mathrm{~cm}$ glass-bottom dishes (WillCo-dish ${ }^{\circledR}$ Glass Bottom Dishes, the Netherlands). The spontaneous action potentials (AP) were recorded from hiPSC-
CMs in normal Tyrode's solution ((in mM): NaCl 140, KCl 5.4, $\mathrm{CaCl}_{2}$ 1.8, $\mathrm{MgCl}_{2}$ 1, glucose 10, HEPES 10 , pH 7.40 with $\mathrm{NaOH}$ ) under current-clamp conditions by an Axopatch 200B patch clamp amplifer (Axon instrument, USA). Patch pipettes, with a resistance of 2-4 M $\Omega$, were pulled by a horizontal puller (Model P-97, Sutter Instrument, USA), and filled with an internal solution containing (in $\mathrm{mM}$ ): $\mathrm{KCl} 130, \mathrm{MgCl}_{2} 1, \mathrm{MgATP} 3$, EGTA 10 , and HEPES 10, pH 7.20 with $\mathrm{KOH}$. In addition, the effect of isoproterenol (ISO, $1 \mu \mathrm{M}$ ) was tested on ventricular-like hiPSCCMs.

\section{Confocal $\mathrm{Ca}^{2+}$ Imaging}

$\mathrm{Ca}^{2+}$ transients and $\mathrm{Ca}^{2+}$ sparks were recorded in ventricularlike hiPSC-CMs using a LSM-710 laser scanning confocal microscope (Carl Zeiss, Inc Germany) with a $40 \times, 1.3$ numerical aperture oil immersion objective and axial resolutions of $1.5 \mu \mathrm{m}$ [12]. Briefly, cells were loaded with $6 \mu \mathrm{g} / \mathrm{mL}$ Fluo- 4 AM for $15 \mathrm{~min}$ at $37^{\circ} \mathrm{C}$, and than were placed in the experimental chamber containing normal Tyrode's solution. Fluo-4 was excited at $488 \mathrm{~nm}$, and fluorescence emission was measured at $>505 \mathrm{~nm}$. Images were acquired in the line-scan (X-T) mode with 512 pixels (pixel intervals of $0.15 \mu \mathrm{m}$ ) per line at a rate of $3 \mathrm{~ms}$ per scan. Two-dimensional images were obtained with the confocal microscope operating in the frame-scan (X-Y, $512 \times 512$ pixels) mode. SR $\mathrm{Ca}^{2+}$ load was estimated by rapid application of $10 \mathrm{mM}$ caffeine with a multi-channel rapid application system.

The intracellular free $\mathrm{Ca}^{2+}\left(\left[\mathrm{Ca}^{2+}\right]_{\mathrm{i}}\right)$ concentration was determined at the end of $\mathrm{Ca}^{2+}$ imaging experiment by the ionomycin method (Text S1 and Figure S1).

\section{Statistical Analysis}

$\mathrm{Ca}^{2+}$ sparks, $\mathrm{Ca}^{2+}$ transients, and $\mathrm{SR} \mathrm{Ca}^{2+}$ contents were analyzed using a computer program written in IDL 5.4 software, as previously described [13]. Results were expressed as mean \pm standard error of the mean (SEM). Statistical significance was determined using Student- $t$ test or non-parametric Kruskal-Wallis test, when appropriate. A $p$ value $<0.05$ was considered to be statistically significant.

\section{Results}

\section{Characterization of hiPSCs}

hiPSC lines showed characteristic hESC-like morphology and comparable expression of hESG pluripotent markers including Oct-4, SSEA-4, TRA-1-81 and TRA-1-60 (Figure 1A). They formed teratoma in SCID mice and maintained normal karyotypes (data not shown).

\section{Cardiomyocyte Differentiation of hiPSCs}

Under cardiac differentiation condition, spontaneously contracting EBs were derived from hiPSC lines after 15 days. Dissociated hiPSC-CMs in the small clusters containing 15 30 CMs with uniformed subtypes (Figure 1Ba), were found to express sarcomeric alpha-actinin ( $\alpha$-actinin) and beta-myosin heavy chain $(\beta-\mathrm{MHC})$ with cross striations that were typical of CMs derived from hESCs (Figure $1 \mathrm{Bb}, \mathrm{c}$ ). Moreover, three subtypes of CMs were identified including ventricular-, atrial- and nodal-like CMs (V-CMs, A-CMs and N-CMs) were identified in hiPSC-CMs (Figure 1G). The subtypes of hiPSC-CMs were determined by their typical AP properties including, action potential amplitude (APA), action potential duration (APD) and $\mathrm{dV} / \mathrm{dtmax}$. From a total of 100 cardiomyocytes examined, the percentages of $\mathrm{V}-\mathrm{CMs}, \mathrm{A}-\mathrm{CM}$ s and $\mathrm{N}-\mathrm{CM}$ s were about $61 \%$, $17.4 \%$ and $21.6 \%$, respectively (Table $\mathrm{S} 1$ ). It was noted that small 
A
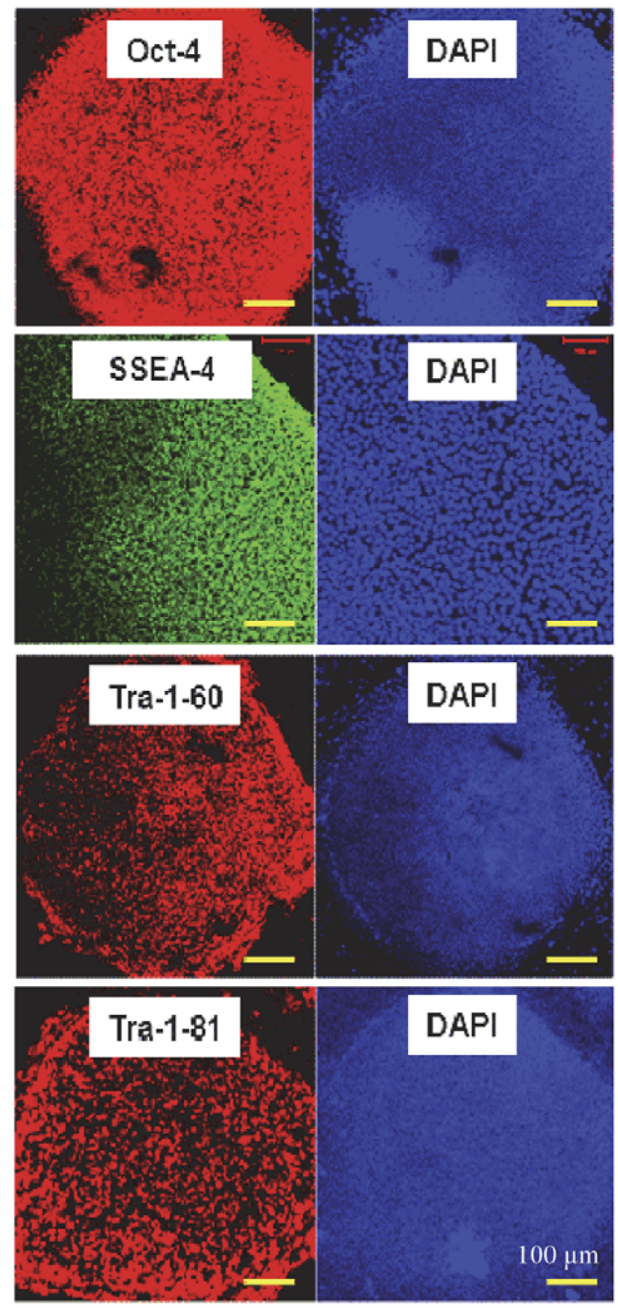

C

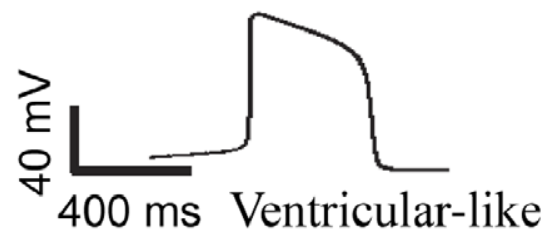

B
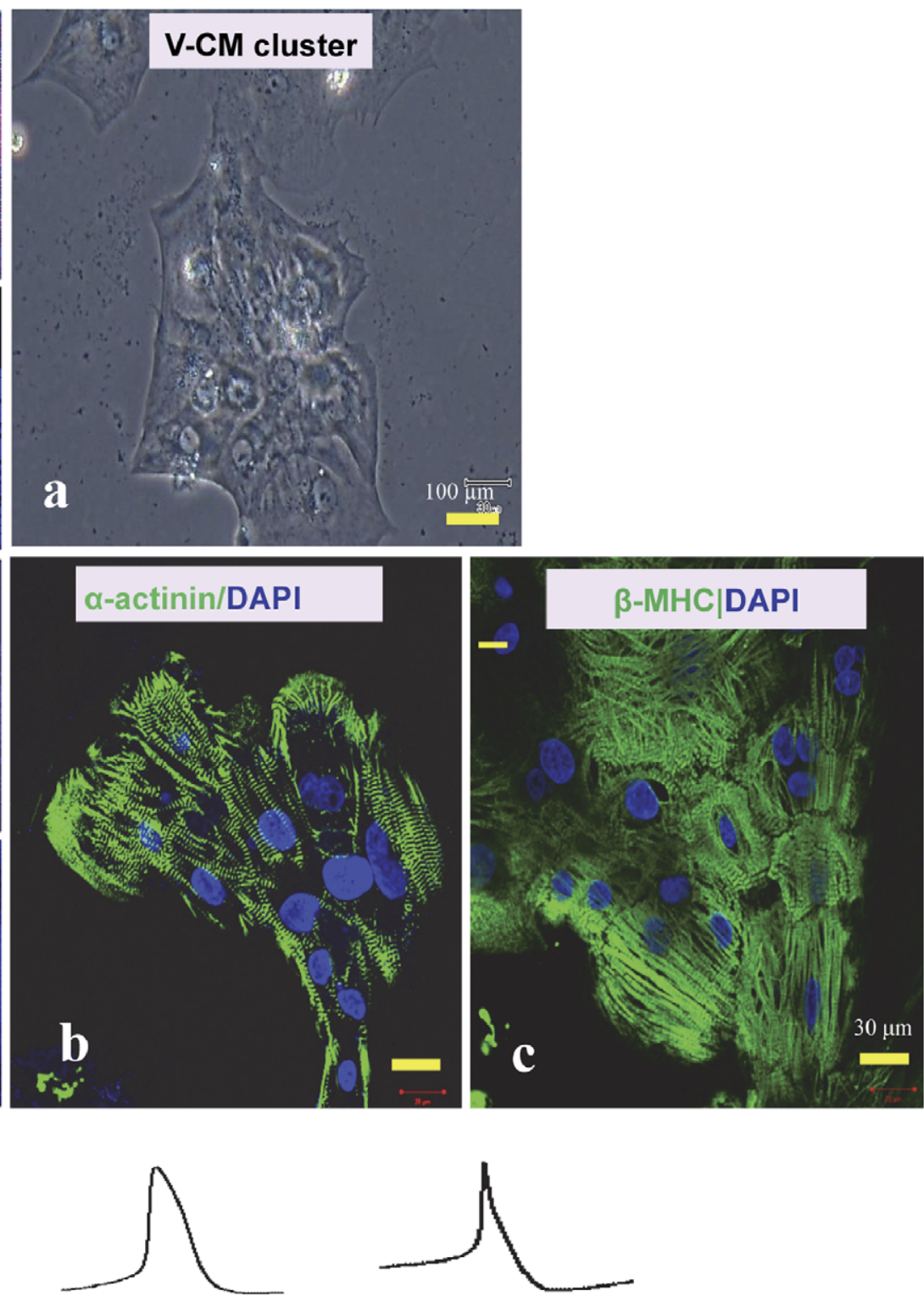

Nodal-like

D

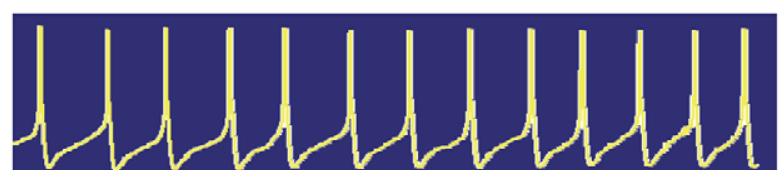

Before $47 / 200 \mathrm{~ms}$

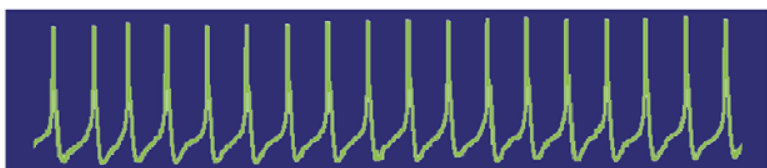

After ISO $(1 \mu \mathrm{M})$

\section{$67 / 200 \mathrm{~ms}$}

Figure 1. Characterization of hiPSCs and hiPSC-derived CMs. (A) Immunofluorescent staining of hiPSC colonies with antibodies against Oct-4, SSEA-4, TRA-1-60 and TRA-1-81. (B) The hiPSC-CMs differentia4ed from above hiPSC line. (Ba) The phase-contrast light micrograph images of a V-CM cluster. (Bb and $\mathrm{BC}$ ) Immunofluorescent staining hiPSC-CMs with antibodies against alpha-actinin and beta-MHC, respectively. Nuclei were stained with DAPI. (C) Action potential traces of ventricular-, atrial- and nodal-like CMs derived from hiPSCs. (D) Response of a ventricular-like hiPSC-CM to ISO recorded with patch-clamp. Abbreviations: ISO, isoproterenol.

doi:10.1371/journal.pone.0055266.g001 
clusters of cardiomyocytes (15 30 cells) dissociated from contracting EBs tended to contain exclusively homogenous subtypes of V-CMs and N-CMs (See Text S1). Furthermore, hiPSC-derived $\mathrm{V}$-CMs $(\mathrm{n}=5)$ showed a classical response towards ISO at minimal effective dose of $1 \mu \mathrm{M}$ that induced contractions per $100 \mathrm{~ms}$ at baseline and post ISO treatment at 26.4 \pm 5.2 and $35.2 \pm 6.4(\mathrm{p}<0.001)$ respectively (Figure 1D). However, atrial-and nodal-like CMs were not tested due to low yield of such subtypes in the hiPSC-CM preparation. Collectively, our data confirmed that hiPSC-CMs displayed cardiac structures and physiological function of cardiomyocytes similar to those of hESC-GMs.

\section{Spontaneous $\mathrm{Ca}^{2+}$ Transients in hiPSC-CMs}

Figure $2 \mathrm{Ab}$ shows representative $\mathrm{Ca}^{2+}$ transients obtained from sequential images recorded by a frame-scan mode in single hiPSCCM. A typical line-scan image of $\mathrm{Ca}^{2+}$ transient and its average fluorescence intensity were shown in Figure 2B and 2C. The average peak amplitude of $\mathrm{Ca}^{2+}$ transients $\left(\mathrm{F} / \mathrm{F}_{0}\right)$ was $3.8 \pm 0.7$ in hiPSC-CMs. To observe spread patterns of $\mathrm{Ca}^{2+}$ transients of hiPSC-CMs, transverse line-scan images of $\mathrm{Ca}^{2+}$ transient were performed. As shown in Figure 2Da, $\mathrm{Ca}^{2+}$ increased first at the periphery of the cell before propagating towards the centre of the cell with a mean time delay of $46 \pm 15 \mathrm{~ms}(\mathrm{n}=7)$ (Figure 2Db). Calibration of $\left[\mathrm{Ca}^{2+}\right]_{\mathrm{i}}$ was performed as described in Text $\mathrm{S} 1$ and Figure S1.

In contrast to hiPSG-CMs, field stimulation evoked a rapid and uniform increase in intracellular $\mathrm{Ca}^{2+}$, and then $\mathrm{Ca}^{2+}$ quickly dropped homogeneously to resting levels in adult rat cardiomyocytes $\left(\mathrm{n}_{\text {rat }}=5, \mathrm{n}_{\text {cell }}=12\right)$. The average amplitude of $\mathrm{Ca}^{2+}$ transients $\left(\mathrm{F} / \mathrm{F}_{0}\right)$ was $3.5 \pm 0.6$ (Figure $\mathrm{S} 2$ ).

\section{Spontaneous $\mathrm{Ca}^{2+}$ Sparks in hiPSC-CMs}

As shown in Figure 3A, serial frame-scan images on the same location of hiPSC-CMs showed a spontaneous elevation of local $\mathrm{Ca}^{2+}$ or $\mathrm{Ca}^{2+}$ sparks occurred inside the cytoplasm (arrow) at different times. To better characterize the spatial and temporal properties of $\mathrm{Ca}^{2+}$ sparks, line-scan imaging was carried out to monitor $\mathrm{Ca}^{2+}$ dynamics at $3 \mathrm{~ms}$ resolution in hiPSC-CMs. Fluorescence (the ratio of fluorescence to background fluorescence $\left.\left(\mathrm{F} / \mathrm{F}_{0}\right)\right)$ profiles of $\mathrm{Ca}^{2+}$ sparks (bottom) were shown in Figure $3 \mathrm{~B}$. The repetitive $\mathrm{Ca}^{2+}$ sparks shown in Figure $3 \mathrm{~B}$ indicated that individual sites could be repeatedly activated to generate $\mathrm{Ca}^{2+}$ sparks, even during the occurrence of spontaneous $\mathrm{Ca}^{2+}$ transients. In adult rat cardiomyocytes, repetitive $\mathrm{Ca}^{2+}$ sparks were seldom observed $\left(<0.5 \%\right.$ in present experiment, $\left.\mathrm{n}_{\text {rat }}=5, \mathrm{n}_{\text {cell }}=31\right)$ (Figure S3).

\section{Unique Characteristics of Spontaneous $\mathrm{Ca}^{2+}$ Sparks in hiPSC-CMs}

Figure 4Aa, b shows two typical line-scan images of $\mathrm{Ca}^{2+}$ sparks. An overlay of 160 original $\mathrm{Ca}^{2+}$ sparks was shown in Figure 4Ac. The spatial widths of $\mathrm{Ca}^{2+}$ sparks (Figure 4Ca,b) show that $\mathrm{Ca}^{2+}$ diffusion from the center of $\mathrm{Ca}^{2+}$ sparks to periphery was asymmetric, indicating that the distribution of RyRs in a cluster of $\mathrm{Ca}^{2+}$ release channels is anomalous or inhomogeneous in hiPSC-CMs. $\mathrm{Ca}^{2+}$ sparks also present multiple ridges in the threedimensional plots (Figure 4Ba,b) and temporal profiles (Figure 4Da,b) of $\mathrm{Ca}^{2+}$ sparks, suggesting the these $\mathrm{Ca}^{2+}$ sparks may originate from one or several different clusters of RyRs. About $90 \%$ of $\mathrm{Ca}^{2+}$ sparks possess this temporal-spatial feature. However, the spatial width in an overlay of $\mathrm{Ca}^{2+}$ spark showed a symmetrical profile (Figure 4Cc).
In order to further determine the characteristics of $\mathrm{Ca}^{2+}$ sparks, we analyzed the amplitude $\left(\mathrm{F} / \mathrm{F}_{0}\right)$, spatial size (FWHM: full width at half maximum) or duration (FDHM: full duration at half maximum) of spontaneous $\mathrm{Ca}^{2+}$ sparks. Figure $4 \mathrm{E}-\mathrm{G}$ showed the histogram for F/F 0 , FDHM and FWHM of $\mathrm{Ca}^{2+}$ sparks which we deduced the relationship between the amplitude and size distributions of $\mathrm{Ca}^{2+}$ sparks and the population of $\mathrm{Ca}^{2+}$ sparks from their histogram plots. The mean values for $\mathrm{F} / \mathrm{F}_{0}$, FWHM and FDHM were $1.64 \pm 0.04,2.31 \pm 0.03 \mu \mathrm{m}$ and $30.9 \pm 0.6 \mathrm{~ms}$, respectively. $\mathrm{Ca}^{2+}$ sparks between hiPSC-CMs and adult ventricular myocytes $\left(\mathrm{n}_{\text {spark }}=302\right)$ have similar characteristics of $\mathrm{Ca}^{2+}$ sparks (Table $\mathrm{S} 2$ ).

\section{L-type $\mathrm{Ca}^{2+}$ Channels Contributes to Spontaneous $\mathrm{Ca}^{2+}$ Sparks and $\mathrm{Ca}^{2+}$ Transients}

To examine whether some of $\mathrm{Ca}^{2+}$ sparks were triggered by activation of RyRs associated with spontaneous L-type $\mathrm{Ca}^{2+}$ channel openings, effect of nifedipine $(5 \mu \mathrm{M})$ on the rate of occurrence of spontaneous $\mathrm{Ca}^{2+}$ sparks was observed. As presented in Figure 5A and 5B, inhibition of L-type $\mathrm{Ca}^{2+}$ channels by nifedipine significantly reduced the frequency of occurrence of $\mathrm{Ca}^{2+}$ sparks without affecting F/F, FDHM and FWHM of $\mathrm{Ca}^{2+}$ sparks (Figure 5C-E). Thus, nifedipine treatment had no significant effect on characteristics of individual $\mathrm{Ca}^{2+}$ sparks, indicating that nifedipine-sensitive and nifedipine-insensitive $\mathrm{Ca}^{2+}$ sparks are indistinguishable by virtue of their unitary properties. Additionally, nifedipine led to the complete elimination of $\mathrm{Ca}^{2+}$ transients in hiPSC-CMs (Figure S4). Therefore, $\mathrm{Ca}^{2+}$ influx via Ltype $\mathrm{Ca}^{2+}$ channels contributes to whole-cell $\mathrm{Ca}^{2+}$ transients.

\section{L-type $\mathrm{Ca}^{2+}$ Channels Blockade did not Affect SR $\mathrm{Ca}^{2+}$ Load}

SR $\mathrm{Ca}^{2+}$ load can directly affect $\mathrm{Ca}^{2+}$ transient amplitudes and $\mathrm{Ca}^{2+}$ spark characteristics. We therefore assessed effect of nifedipine on SR $\mathrm{Ca}^{2+}$ load in hiPSC-CMs. Figure $5 \mathrm{~F}$ and $5 \mathrm{G}$ shows the line-scan images and amplitudes of $\mathrm{Ca}^{2+}$ transients elicited by the application of $10 \mathrm{mM}$ caffeine under both control and in the presence of nifedipine. SR $\mathrm{Ca}^{2+}$ load was unaffected by nifedipine ( $4.9 \pm 0.5$ in nifedipine vs $5.1 \pm 0.4$ in control) which indicated that L-type $\mathrm{Ca}^{2+}$ channels blockade did not affect SR $\mathrm{Ca}^{2+}$ load in hiPSC-CMs.

Effects of Extracellular $\mathrm{Ca}^{2+}$ Concentration on $\mathrm{Ca}^{2+}$ Sparks $\mathrm{Ca}^{2+}$ influx is an important trigger for $\mathrm{SR} \mathrm{Ca}^{2+}$ release. To observe effect of extracellular $\mathrm{Ca}^{2+}$ concentration on $\mathrm{Ca}^{2+}$ sparks, $5 \mathrm{mM} \mathrm{CaCl}_{2}$ was applied in extracellular solution. Figure $6 \mathrm{~A}$ shows the line-scan images of spontaneous $\mathrm{Ca}^{2+}$ sparks before and after the application of $5 \mathrm{mM} \mathrm{CaCl}_{2}$. It is clear that the frequency of $\mathrm{Ca}^{2+}$ sparks was $5.4 \pm 0.8$ sparks $/ 100 \mu \mathrm{m} . \mathrm{s}$ in control, significantly increased to $10.4 \pm 0.5$ sparks $/ 100 \mu \mathrm{m} . \mathrm{s}$ after application of $5 \mathrm{mM} \mathrm{CaCl}_{2}$ (Figure 6B). The histograms for FDHM and FWHM of $\mathrm{Ca}^{2+}$ sparks indicated an increase in big spark populations, the mean values for FDHM and FWHM were increased from $31.6 \pm 0.6 \mathrm{~ms}$ and $2.29 \pm 0.03 \mu \mathrm{m}$ in control to $32.1 \pm 0.7 \mathrm{~ms}$ and $2.33 \pm 0.04 \mu \mathrm{m}($ All $* P<0.05)$ in the presence of $5 \mathrm{mM} \mathrm{CaCl} 2$ (before $\mathrm{n}_{\text {spark }}=143 ;$ after $\mathrm{n}_{\text {spark }}=318 ; \mathrm{n}_{\text {cell }}=10$ ), respectively (Figure 6D, E). However, the amplitude of $\mathrm{Ca}^{2+}$ sparks in the presence of $5 \mathrm{mM} \mathrm{CaCl}_{2}(1.48 \pm 0.02)$ was significantly lower than those in control $(1.51 \pm 0.04)\left({ }^{*} P<0.05\right)$ (Figure $\left.6 \mathrm{C}\right)$. The results showed that elevated extracellular $\mathrm{Ca}^{2+}$ concentration resulted in an increase in big spark populations. 
$\mathbf{A}$

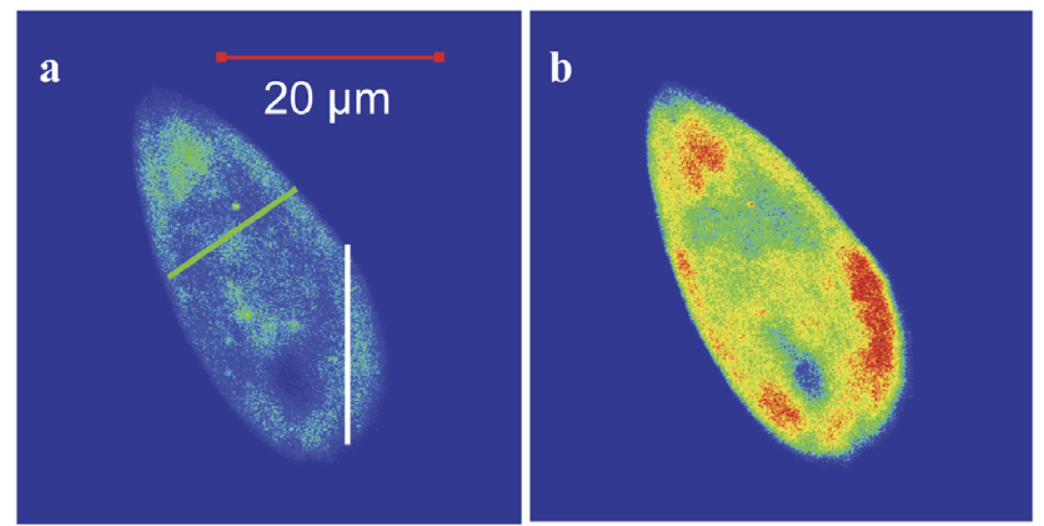

B

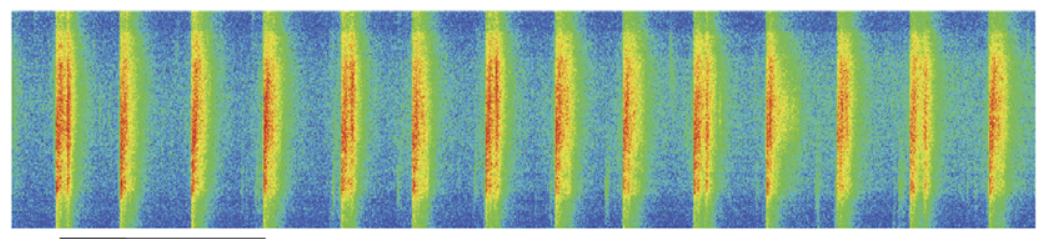

$4 \mathrm{~s}$

C

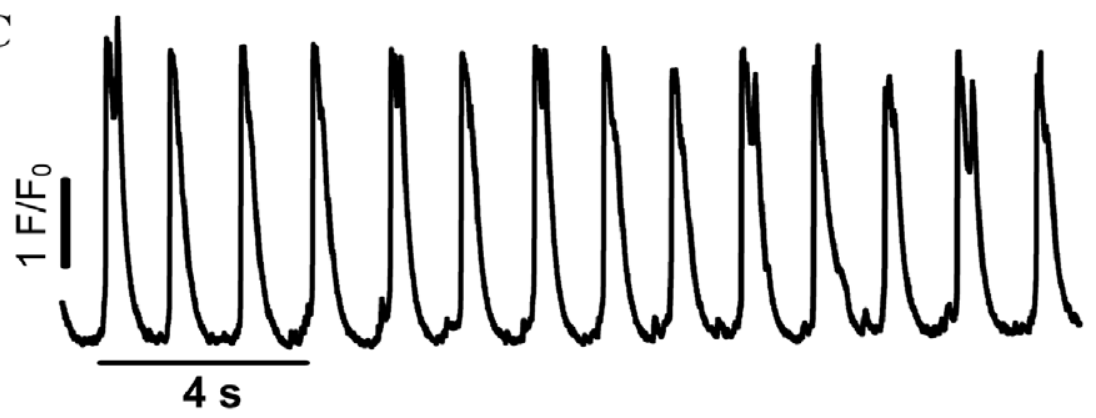

$\mathrm{D}$

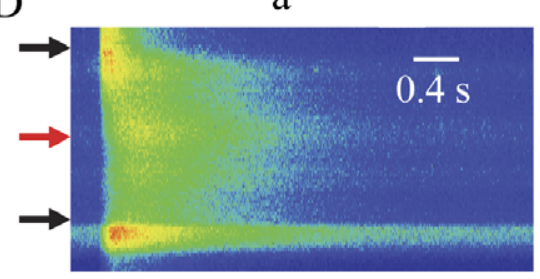

$\mathrm{b}$

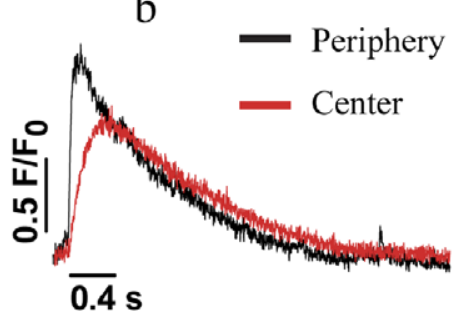

Figure 2. Spontaneous $\mathrm{Ca}^{2+}$ transients in hiPSC-CMs. (A) Representative frame-scan (X-Y mode) images of spontaneous $\mathrm{Ca}^{2+}$ transients (a and b). (B) A typical line scan (X-T mode) image of spontaneous $\mathrm{Ca}^{2+}$ transients obtained from white line in panel $\mathrm{Aa}$ and (C) the corresponding amplitudes $\left(F / F_{0}\right)$ of $\mathrm{Ca}^{2+}$ transients $(n=16)$. (D) A representative transverse line scan (X-T mode) image obtained from green line in panel Aa (a) and the corresponding intensity profiles (b) of $\mathrm{Ca}^{2+}$ transients. Abbreviations: $F / F_{0}$, fluorescence $(F)$ normalized to baseline fluorescence $\left(F_{0}\right)$; $s$, seconds. doi:10.1371/journal.pone.0055266.g002

\section{Effects of Ryanodine on $\mathrm{Ca}^{2+}$ Sparks}

$\mathrm{Ca}^{2+}$ sparks are local and transient calcium release events from a cluster of RyRs in the SR. Delineating the properties of RyRs in hiPSC-CMs is thus a matter of fundamental importance to $\mathrm{Ca}^{2+}$ sparks. In the present study, the spark frequency FDHM and FWHM showed significant increase $(\mathrm{P}<0.05)$, whereas $\mathrm{F} / \mathrm{F}_{0}$ was not significant changed after application of $50 \mathrm{nM}$ ryanodine (before $\mathrm{n}_{\text {spark }}=163$; after $\mathrm{n}_{\text {spark }}=347 ; \mathrm{n}_{\text {cell }}=11$ ), when compared with control (Figure $7 \mathrm{~A}-\mathrm{E}$ ). These results indicated that ryanodine could increase the size of $\mathrm{Ca}^{2+}$ sparks in hiPSC-CMs.

\section{Discussion}

In adult cardiac myocytes, $\mathrm{Ca}^{2+}$ spark is an infrequent and stochastic elementary event of $\mathrm{Ca}^{2+}$ release [2]. $\mathrm{Ca}^{2+}$ sparks are often associated with the transverse tubules (TTs) at the Z-disk of a sarcomere where RyRs and L-type $\mathrm{Ca}^{2+}$ channels colocalize $[12,14,15]$. Furthermore, repetitive $\mathrm{Ca}^{2+}$ sparks may originate from the same RyR cluster [16]. In the present study, repetitive $\mathrm{Ca}^{2+}$ sparks emerged at the same sites were observed in hiPSCGMs. In contrast, such phenomenon has rarely been reported in adult quiescent ventricular myocytes [16].

Similar to previous reports [17-19], the $\mathrm{Ca}^{2+}$ sparks in hiPSCCMs were not associated with $\mathrm{Ca}^{2+}$ transients or $\mathrm{Ca}^{2+}$ wave propagation throughout the cells (Figure $3 \mathrm{~B}$ ). This phenomenon 

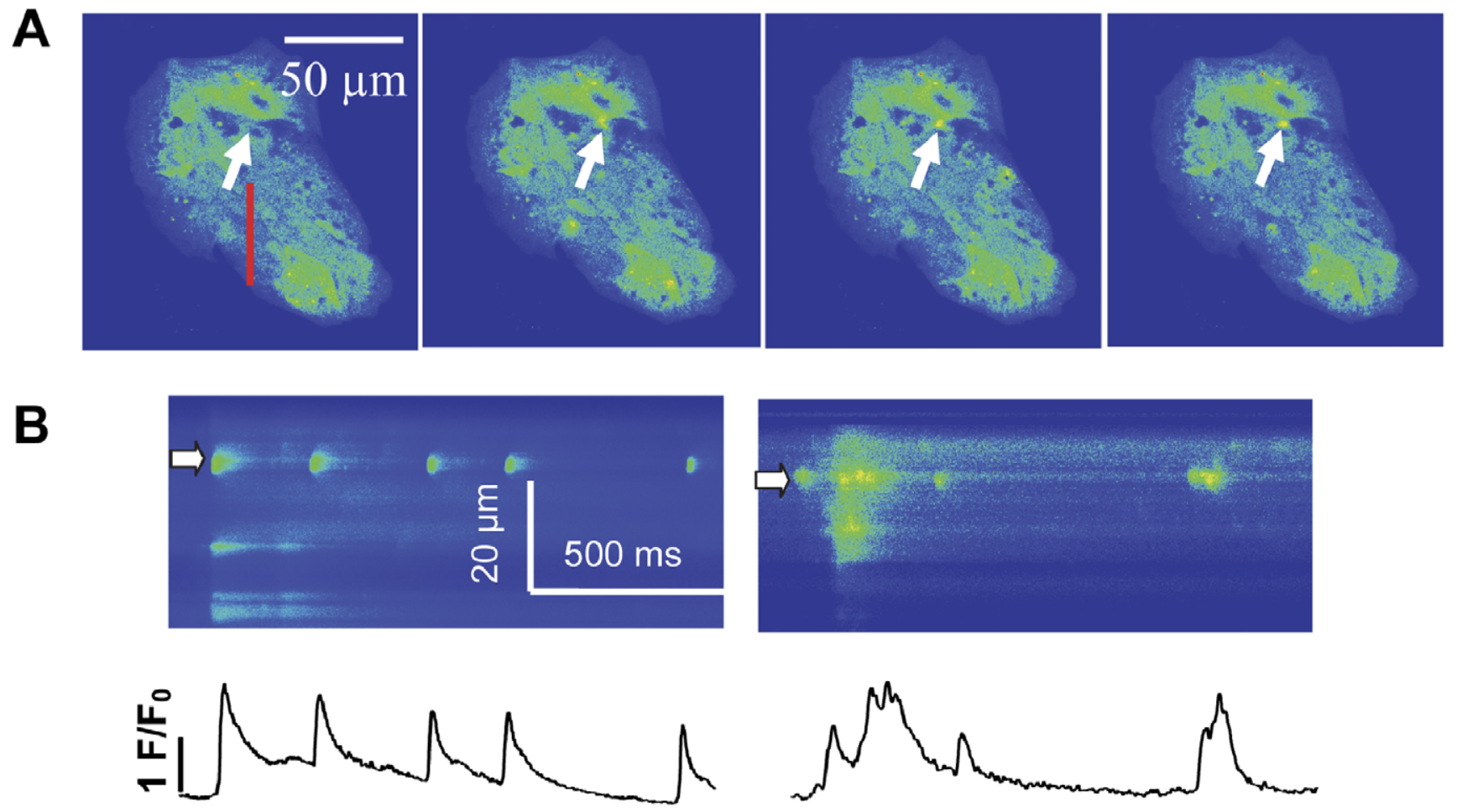

Figure 3. Spontaneous $\mathrm{Ca}^{2+}$ sparks in hiPSC-CMs. (A) Confocal images of spontaneous sparks were recorded in $X-Y$ scanning mode. Representative spontaneous $\mathrm{Ca}^{2+}$ sparks occurred at the same site. (B) Two representative line scan (X-T mode) images of $\mathrm{Ca}^{2+}$ sparks obtained from red line in panel $A$ at different times (top) and the intensity-time profiles of $\mathrm{Ca}^{2+}$ sparks at sites indicated by white arrows (bottom). Abbreviations: $\mathrm{F} /$ $F_{0}$, fluorescence $(F)$ normalized to baseline fluorescence $\left(F_{0}\right)$.

doi:10.1371/journal.pone.0055266.g003

suggests that release units in those cells are separated by critical distances [20].

In adult mammalian ventricular myocytes, the T-tubules are the main site of E-C coupling and ensure spatially and temporally homogenous $\mathrm{Ca}^{2+}$ release throughout the cell [21]. Due to the lack of T-tubule, $\mathrm{Ca}^{2+}$ sparks are restricted to the cell periphery in neonatal cells and rabbit Purkinje cells whereby the SR membrane is associated directly with the plasma membrane which is similar to the dyadic cleft in ventricular myocytes [17-19,22]. Studies with mouse and human ESC-derived CMs have revealed that Ttubules are either absent [23,24], or less developed with poorly organized T-tubule system $[25,26]$. Our present study of hiPSCCMs show a U-shaped $\mathrm{Ca}^{2+}$ wavefront with rise of $\mathrm{Ca}^{2+}$ occurs initially at the cell periphery and then diffuses to the centre of the cell with an obvious delay. This indicates spatial separation between L-type $\mathrm{Ca}^{2+}$ channels and RyRs in ultrastructural organization which is likely due to the lack of t-tubules [7]. Similar findings of such segregation were reported previously $[7,18,27,28]$.

Spontaneous $\mathrm{Ca}^{2+}$ spark could be activated either by the cytosolic $\mathrm{Ca}^{2+}$ affecting the entire population of RyRs, or by $\mathrm{Ca}^{2+}$ entry into myocyte through the L-type channels. It is reported that about $50 \%$ of spontaneous sparks are attributable to spontaneous and infrequent openings of L-type $\mathrm{Ca}^{2+}$ channels at resting membrane potential [12]. The present results showed that blocking the L-type $\mathrm{Ca}^{2+}$ channels by nifedipine reduced over $60 \%$ of the rate of spark occurrence suggesting that $\mathrm{Ca}^{2+}$ sparks in hiPSC-CMs were triggered predominately by the L-type $\mathrm{Ca}^{2+}$ channel dependent triggering mechanisms.
Nifedipine did not inhibit caffeine-induced $\mathrm{Ca}^{2+}$ transients. Similar phenomena were also demonstrated after the application of nifedipine or $\mathrm{Ca}^{2+}$-free extracellular solution in cat ventricular myocytes or hiPSC-CMs [8,29]. Accordingly, the main $\mathrm{Ca}^{2+}$ source for the caffeine-induced $\mathrm{Ca}^{2+}$ transients is not dominated by $\mathrm{Ca}^{2+}$ influx via L-type $\mathrm{Ca}^{2+}$ channels [8]

To study the effect of $\mathrm{Ca}^{2+}$ concentration on $\mathrm{Ca}^{2+}$ sparks, $5 \mathrm{mM} \mathrm{CaCl}{ }_{2}$ was applied to extracellular solution. Under high extracellular $\mathrm{Ca}^{2+}$ condition, spontaneous $\mathrm{Ca}^{2+}$ sparks synchronously activated nearby $\mathrm{Ca}^{2+}$ release units and produced multiple sparks, called a "compound spark" or "macrospark", from neighboring $\mathrm{Ca}^{2+}$ release units [30]. Similar observations were seen in Fig. 6, our findings were consistent with those reported in adult ventricular myocytes [31]. Therefore, $\mathrm{Ca}^{2+}$ sensitivity of RyRs in hiPSC-CMs was similar to those in adult ventricular myocytes. The decrease in the amplitude of sparks might be related to a decrease in the amount of $\mathrm{Ca}^{2+}$ release per RyR opening.

In the present study, ryanodine elevated the rate of spark occurrence and the temporal and spatial properties of $\mathrm{Ca}^{2+}$ sparks, without affecting the amplitude of $\mathrm{Ca}^{2+}$ sparks. RyR2 is the predominant RyR isoform in cardiac muscle, this RyR isoform is essential for E-C coupling and $\mathrm{Ca}^{2+}$ sparks in cardiac myocytes [4]. It was reported that $\mathrm{Ca}^{2+}$ sparks activity was absent after genetic ablation of RyR2 in stem cell-derived cardiomyocytes [4]. The expression of RyR2 gene in hiPSC-CMs has been confirmed previously $[7,8]$. Therefore, our results indicated that a functional RyR2-mediated SR $\mathrm{Ca}^{2+}$ release is present in hiPSC-CMs.

In hiPSC/hESG-CMs, the mechanism of E-C coupling remains contentious. Some reports supported classical model of E-C coupling $[8,32]$. Alternatively, it was suggested that $\mathrm{Ca}^{2+}$ used by 
A

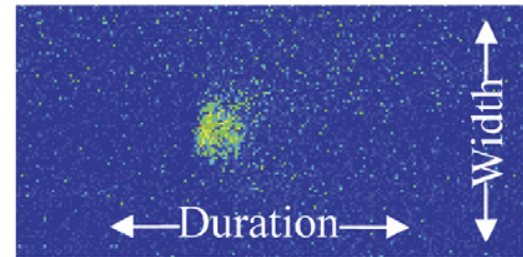

B

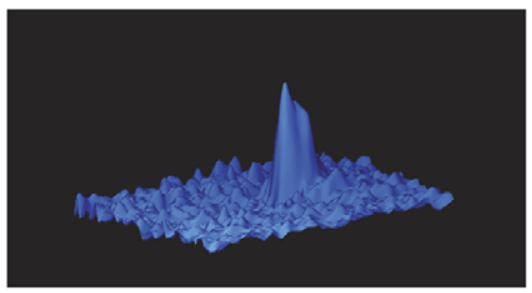

C

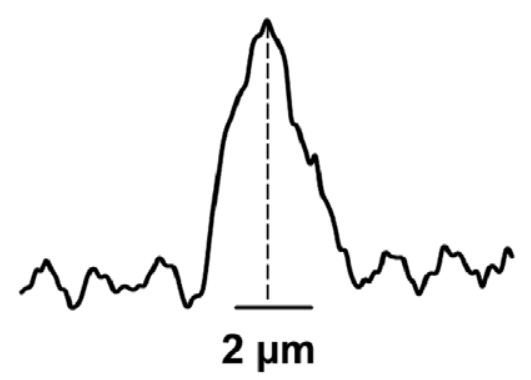

D

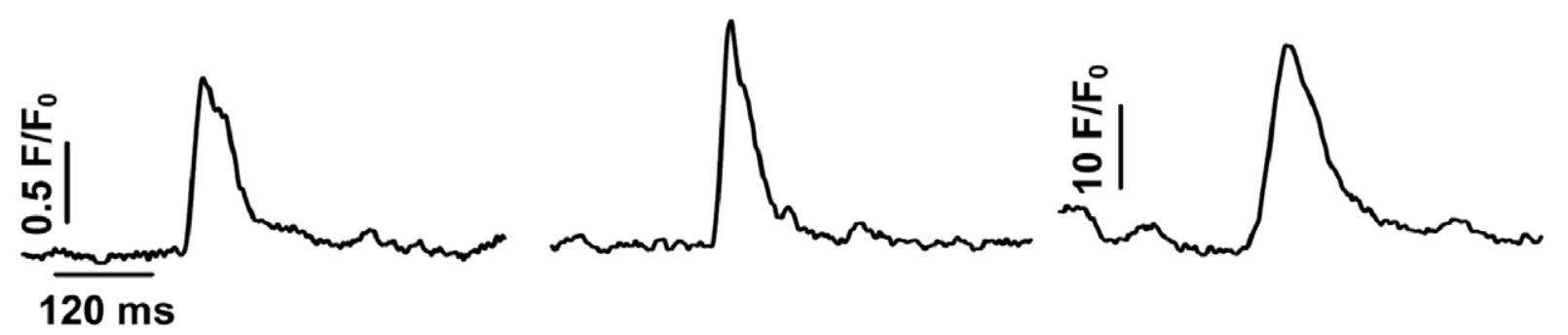

b
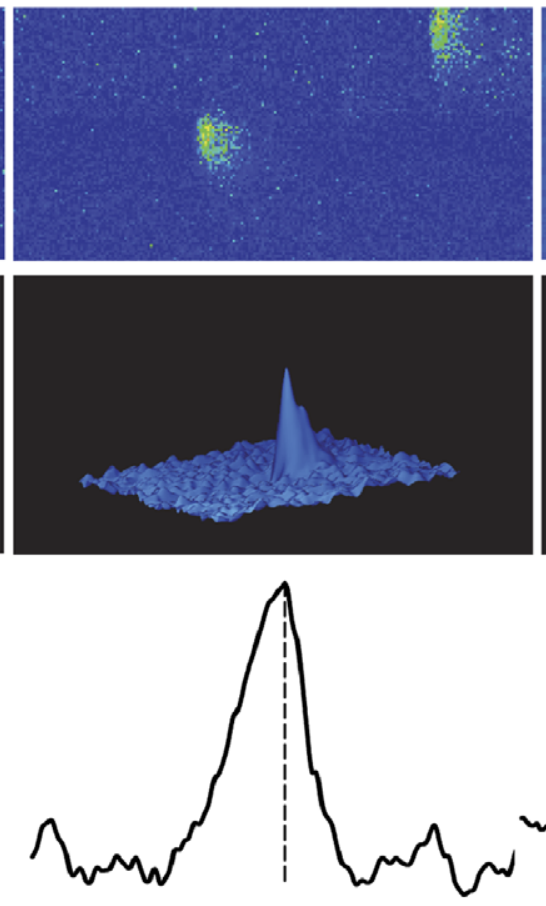

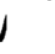

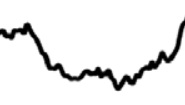

$3 \mu \mathrm{m}$
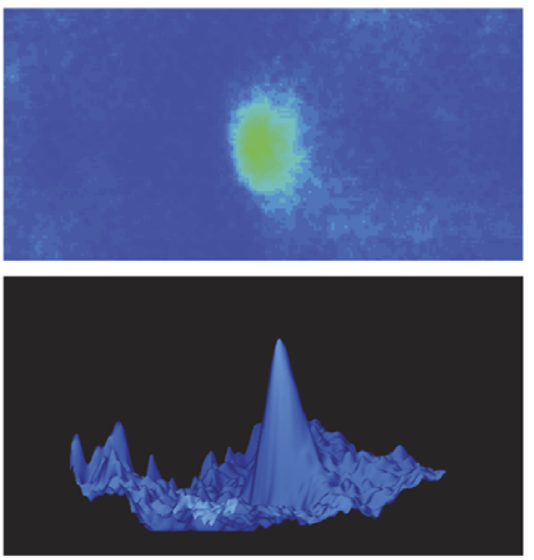

c

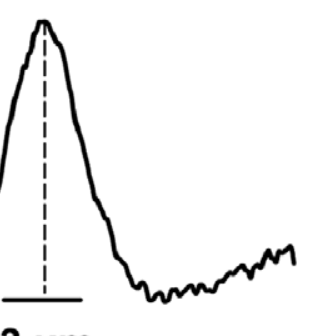

$\mathbf{E}$

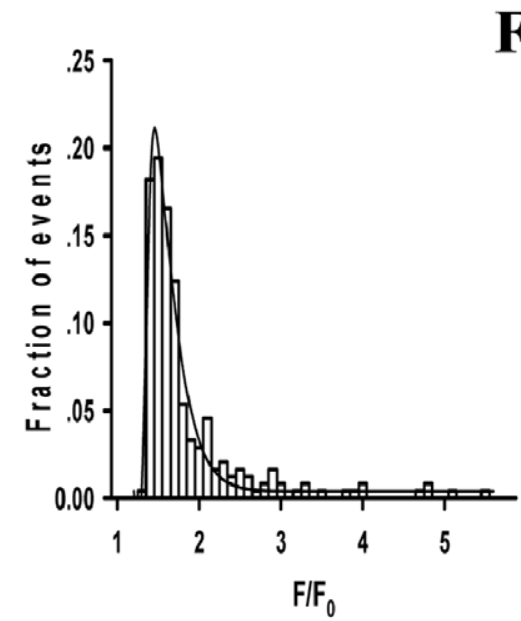

G

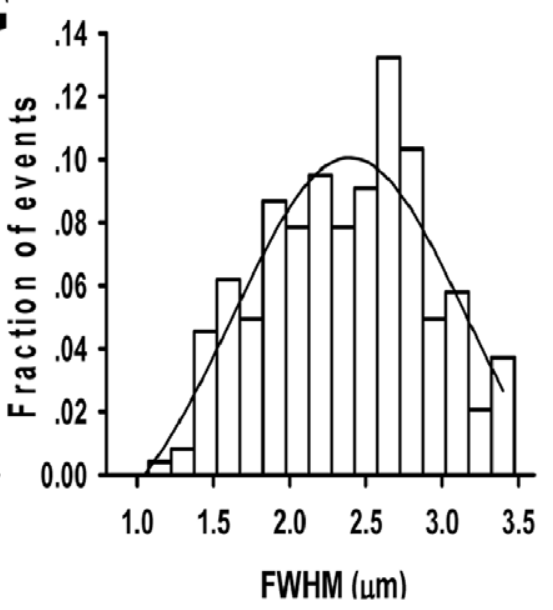

Figure 4. The characteristics of spontaneous $\mathrm{Ca}^{2+}$ sparks in hiPSC-CMs. (A) Two representative $\mathrm{Ca}^{2+}$ sparks (a and b) and an overlay of 160 original $\mathrm{Ca}^{2+}$ sparks (c) were obtained from the line-scan (X-T) images. (B) The three-dimensional surface plot of the $\mathrm{Ca}^{2+}$ spark in panel A. (C) The spatial width of $\mathrm{Ca}^{2+}$ sparks. (D) The duration of $\mathrm{Ca}^{2+}$ sparks. (E-G) show the distributions of $\mathrm{Ca}^{2+}$ sparks for $F / F_{0}$, FDHM and FWHM, respectively. $\mathrm{n}_{\text {cell }}=17, \mathrm{n}_{\text {spark }}=325 .{ }^{*} P<0.05$ vs. control. Abbreviations: $F / F_{0}$, fluorescence $(F)$ normalized to baseline fluorescence $\left(F_{0}\right) ; F D H M$, full duration at half maximum; FWHM, full width at half maximum. doi:10.1371/journal.pone.0055266.g004 
A
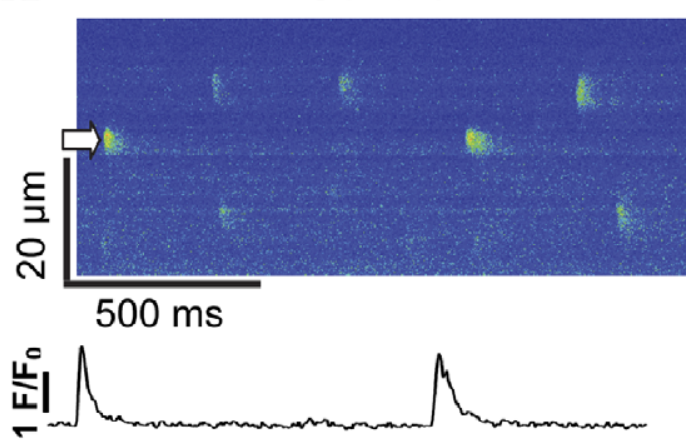

B

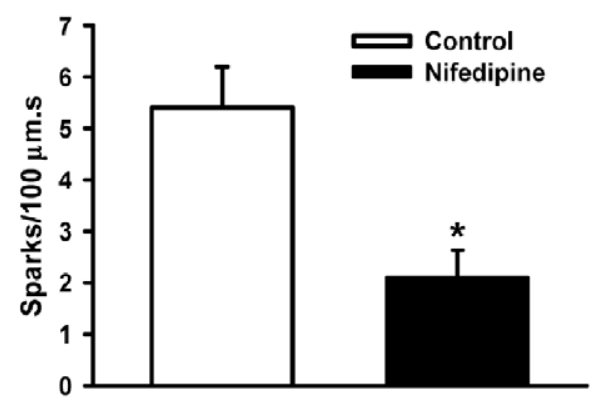

D

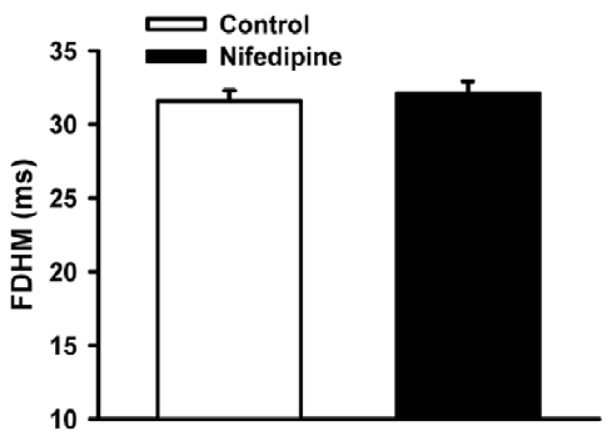

$\mathbf{F}$

\section{Control}

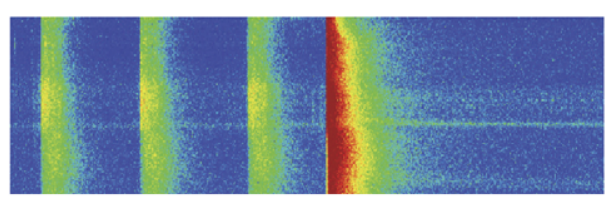

G

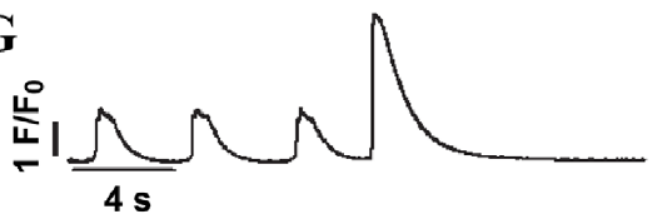

Nifedipine
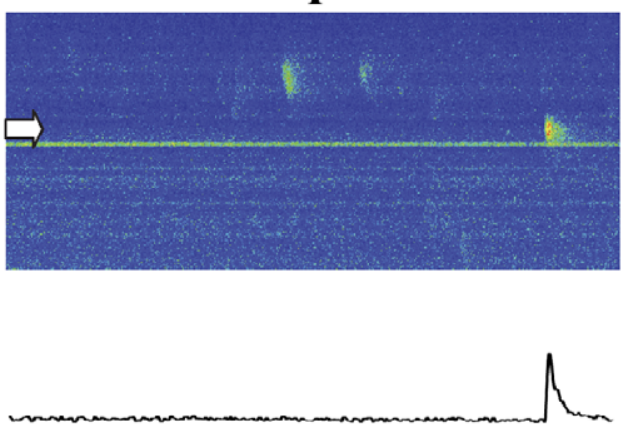

C

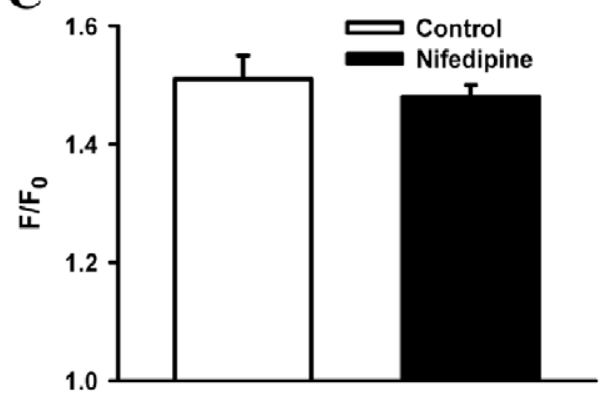

$\mathbf{E}$

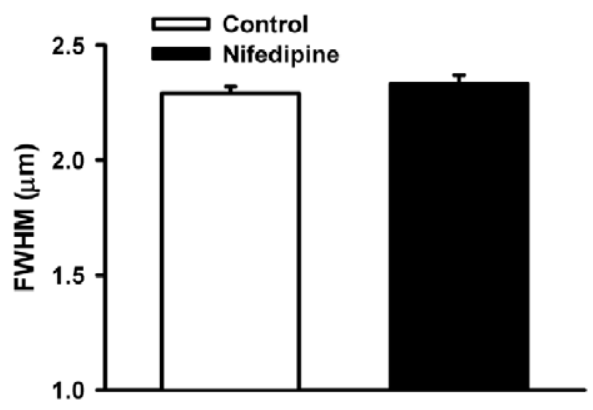

Nifedipine
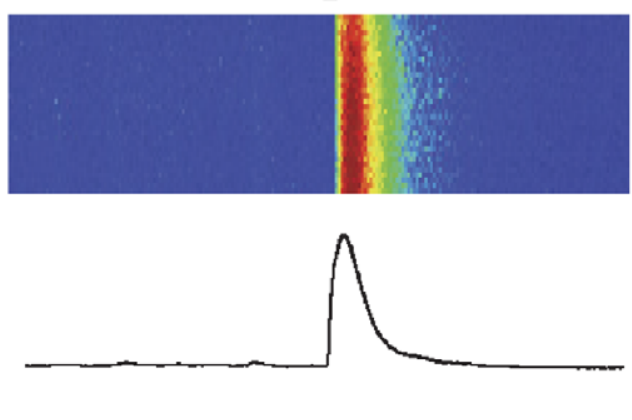

Figure 5. Effects of nifedipine on spontaneous $\mathbf{C a}^{2+}$ sparks and $\mathbf{S R ~ C a}^{2+}$ loads in hiPSC-CMs. (A) Representative line scan (X-T) images of spontaneous $\mathrm{Ca}^{2+}$ sparks (top) and intensity-time profiles of typical sparks at positions denoted by white arrows (bottom) before and after the application of nifedipine. The average values of $\mathrm{Ca}^{2+}$ sparks for frequency $(B), F / F_{0}(C), F D H M(D)$ and FWHM $(E)$ before $\left(n_{\text {spark }}=213\right)$ and after $\left(n_{\text {spark }}=128\right)$ addition of nifedipine. $(F)$ The line-scan images of caffeine-induced $\mathrm{Ca}^{2+}$ transients and $(G)$ the corresponding $F / F_{0}$ profiles before and after the application of nifedipine. $n_{\text {cell }}=12 .{ }^{*} P<0.05$ vs. control. Abbreviations: $F / F_{0}$, fluorescence $(F)$ normalized to baseline fluorescence $\left(F_{0}\right) ; F D H M$, full duration at half maximum; FWHM, full width at half maximum; $s$, seconds. doi:10.1371/journal.pone.0055266.g005 
A

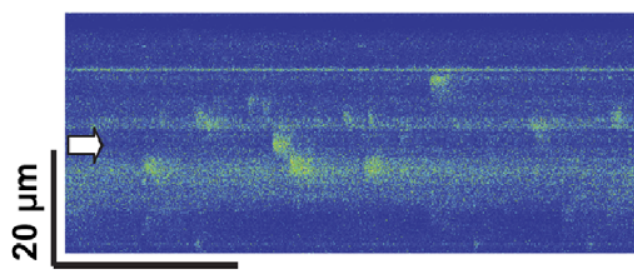

$500 \mathrm{~ms}$

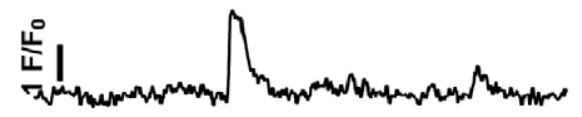

$\mathrm{CaCl}_{2} 5 \mathrm{mM}$
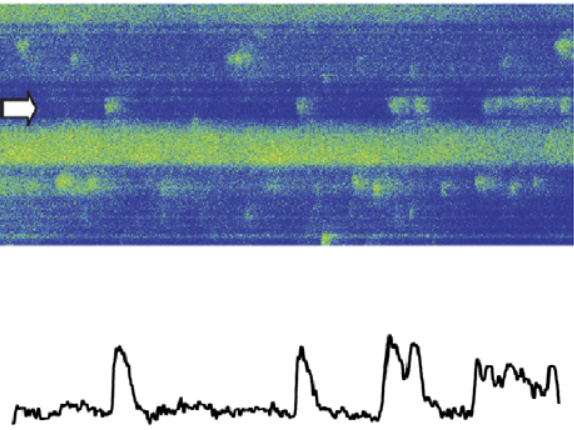

C

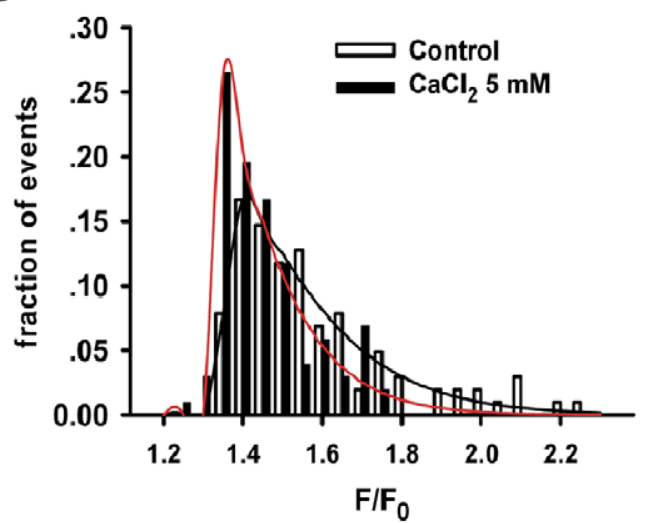

$\mathbf{E}$

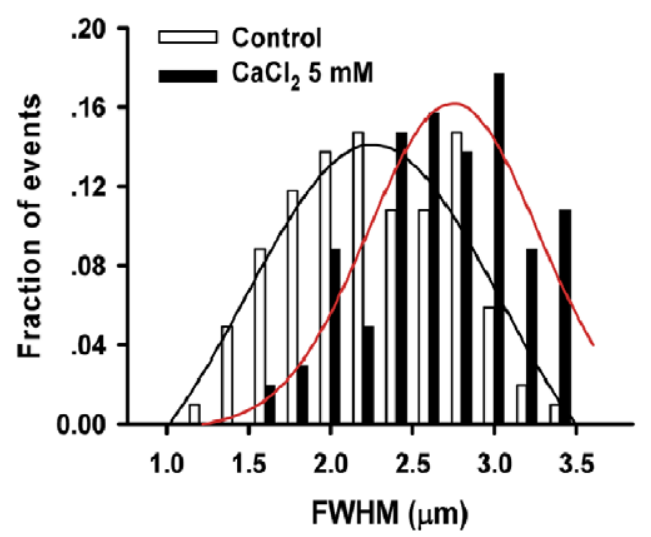

Figure 6. Effects of $\mathrm{CaCl}_{2}$ on spontaneous $\mathrm{Ca}^{2+}$ sparks in hiPSC-CMs. (A) Representative line-scan (X-T) images of spontaneous $\mathrm{Ca}^{2+}$ sparks (top) and the corresponding intensity-time profiles of typical sparks (bottom) before and after the application of $5 \mathrm{mM} \mathrm{CaCl}$. (B) The frequency of $\mathrm{Ca}^{2+}$ sparks. (C), (D) and (E) show the histograms for $F / F_{0}, F D H M$ and FWHM of $\mathrm{Ca}^{2+}$ sparks before $\left(n_{\text {spark }}=143\right)$ and after $\left(n_{\text {spark }}=318\right)$ application of $5 \mathrm{mM} \mathrm{CaCl}$, respectively. $\mathrm{n}_{\text {cell }}=10 .{ }^{*} P<0.05$ vs. control. Abbreviations: $F / F_{0}$, fluorescence $(F)$ normalized to baseline fluorescence $\left(F_{0}\right) ; F D H M$, full duration at half maximum; FWHM, full width at half maximum.

doi:10.1371/journal.pone.0055266.g006

the contractile machinery was provided by transsarcolemmal influx and not by $\mathrm{SR} \mathrm{Ca}^{2+}$ release [33]. In the present study, the elimination of $\mathrm{Ca}^{2+}$ transients and the decrease of $\mathrm{Ca}^{2+}$ spark frequency in the presence of nifedipine demonstrated that $\mathrm{Ca}^{2+}$ transients in hiPSC-CMs were tightly regulated by the CICR mechanism during E-C coupling. To discount inter-line variations, hiPSC lines from additional 3 healthy subjects were examined and similar (no statistical difference) $\mathrm{Ca}^{2+}$ properties were observed among the cardiomyocytes (with same post cardiac differentiation time point) derived from all 4 lines, including the one presented in this study (Table S3). There was no significant difference in $\mathrm{Ca}^{2+}$ spark properties in hiPSC-CMs differentiated from different clones.

Electrophysiological property of pluripotent stem cell-derived CMs may vary due to culture duration of hiPSC-CMs [34]. In our study, cardiomyocytes maintained under culture conditions from 4 to 7 weeks post cardiac differentiation were compared in their 
A
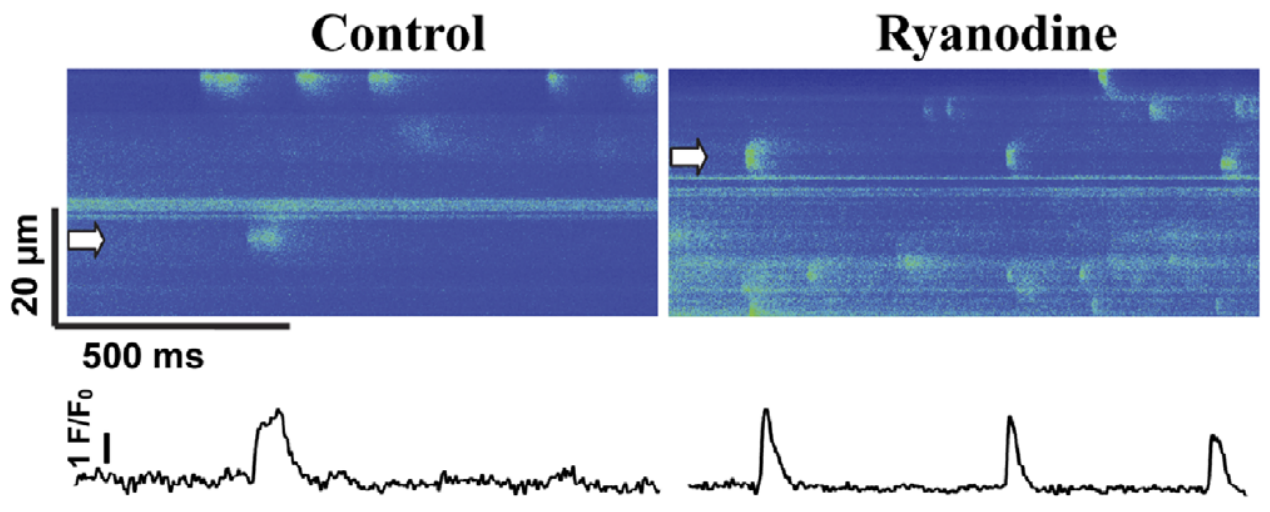

B

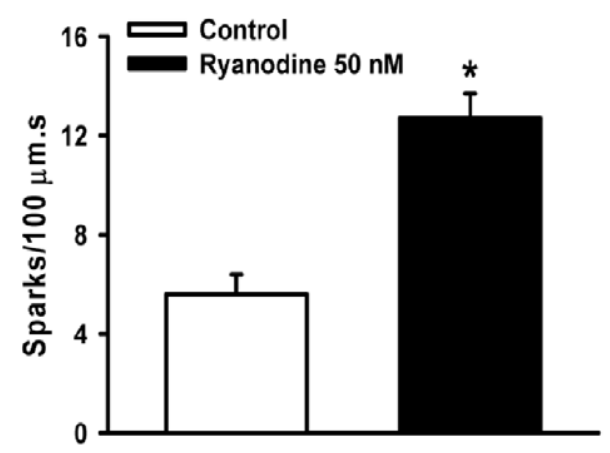

D

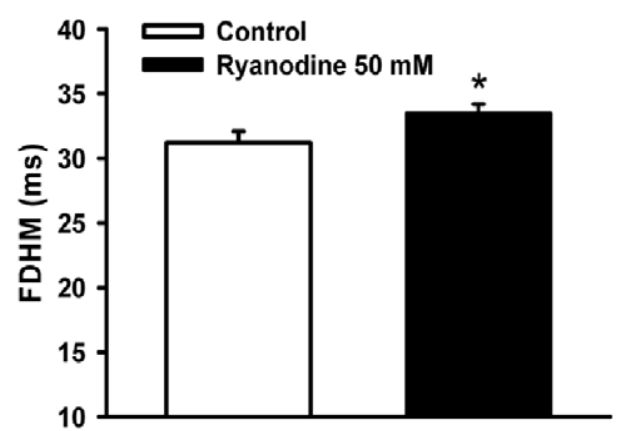

$\mathbf{C}$

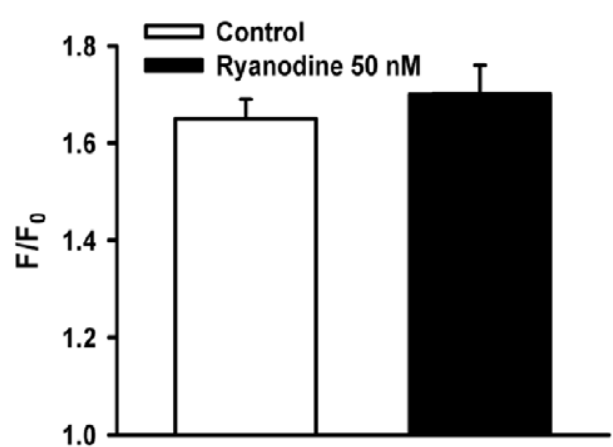

$\mathbf{E}$

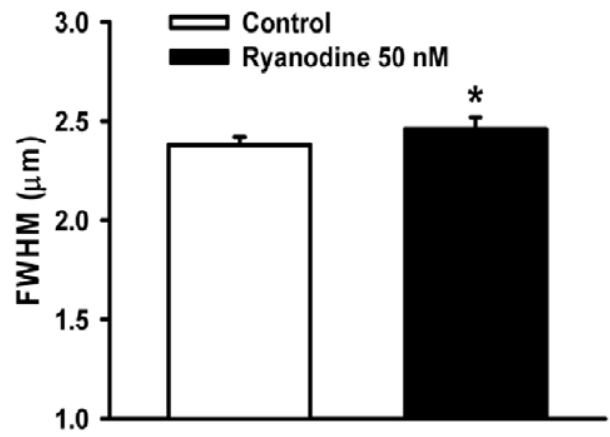

Figure 7. Effects of ryanodine on spontaneous $\mathrm{Ca}^{2+}$ sparks in hiPSC-CMs. (A) Representative line-scan (X-T) images of spontaneous Ca ${ }^{2+}$ sparks (top) and the corresponding intensity-time profiles of typical sparks (bottom) before and after the application of ryanodine. (B-E) show the mean values for frequency, F/F,$F D H M$ and FWHM of $\mathrm{Ca}^{2+}$ sparks before $\left(\mathrm{n}_{\text {spark }}=163\right)$ and after $\left(\mathrm{n}_{\text {spark }}=347\right)$ application of ryanodine, respectively. $\mathrm{n}_{\text {cell }}=11$. ${ }^{*} P<0.05$ vs. control. Abbreviations: $F / F_{0}$, fluorescence $(F)$ normalized to baseline fluorescence $\left(F_{0}\right) ; F D H M$, full duration at half maximum; FWHM, full width at half maximum.

doi:10.1371/journal.pone.0055266.g007

characteristics of $\mathrm{Ca}^{2+}$ sparks and no significant differences were identified (data not shown). Nevertheless, long-term following up studies were not performed due to low yield of cardiac differentiation.

In summary, we identified spontaneous $\mathrm{Ca}^{2+}$ sparks and documented their fundamental characteristics in hiPSC-CMs. We found that the $\mathrm{Ca}^{2+}$ sparks in hiPSC-CMs share similar temporal and spatial properties with adult cardiomyocytes. Moreover, RyRs are functioning in hiPSC-CMs and a majority of spontaneous $\mathrm{Ca}^{2+}$ sparks is L-type $\mathrm{Ca}^{2+}$ channel dependent. However, the $\mathrm{Ca}^{2+}$ sparks in hiPSC-CMs appear to be stochastic with a tendency of repetitive occurrence at some sites. Such phenomenon might be attributed to a heterogeneous array of
RyRs due to the lack of $\mathrm{T}$ tubules or immature T-tubule system in hiPSC-CMs.

\section{Supporting Information}

Figure S1 Measurement of $\left[\mathrm{Ca}^{2+}\right]_{\mathbf{i}}$ by using ionomycin. (A) Representative line scan $(\mathrm{X}-\mathrm{T})$ image of $\mathrm{Ca}^{2+}$ transients before and after the application of ionomycin and EGTA. (B) The fluorescent intensity profiles of $\mathrm{Ca}^{2+}$ transients in $\mathrm{A}$. (C) The $\mathrm{Ca}^{2+}$ concentrations of spontaneous $\mathrm{Ca}^{2+}$ transients were calculated by using equation: $\left[\mathrm{Ca}^{2+}\right] \mathrm{I}=\mathrm{K}_{\mathrm{d}}\left[\left(\mathrm{F}-\mathrm{F}_{\min }\right) /\left(\mathrm{F}_{\max }-\mathrm{F}\right)\right]$. Abbreviations: $\mathrm{K}_{\mathrm{d}}$, the dissociation constant value of a fluorescence; $\mathrm{F}$, the measured fluorescence value; $F_{\max }$, the fluorescence value with 
$2 \mu \mathrm{M}$ ionomycin; $\mathrm{F}_{\min }$, the fluorescence value with $\mathrm{Ca}^{2+}$-free bath solution containing $5 \mathrm{mM}$ EGTA.

(TIFF)

Figure S2 The characteristics of $\mathrm{Ca}^{2+}$ transients in rat cardiomyocytes. A representative line-scan (X-T) image of $\mathrm{Ca}^{2+}$ transient recorded from field stimulated rat cardiomyocyte (top) and the corresponding intensity profiles (bottom) of $\mathrm{Ca}^{2+}$ transient. $\mathrm{n}_{\text {rat }}=5, \mathrm{n}_{\text {cell }}=12$. Abbreviations: $\mathrm{F} / \mathrm{F}_{0}$, fluorescence $(\mathrm{F})$ normalized to baseline fluorescence $\left(\mathrm{F}_{0}\right)$.

(TIFF)

Figure S3 The characteristics of spontaneous $\mathrm{Ca}^{2+}$ sparks in rat cardiomyocytes. (A) A representative line-scan (X-T) image of $\mathrm{Ca}^{2+}$ sparks recorded from rat cardiomyocytes. (B) A typical $\mathrm{Ca}^{2+}$ spark from the cells indicated by arrow in A. (C) The three-dimensional surface plot of the $\mathrm{Ca}^{2+}$ spark in B. (D) The spatial width of $\mathrm{Ca}^{2+}$ spark. (E) The duration of $\mathrm{Ca}^{2+}$ spark. Abbreviations: $\mathrm{F} / \mathrm{F}_{0}$, fluorescence $(\mathrm{F})$ normalized to baseline fluorescence $\left(\mathrm{F}_{0}\right)$.

(TIFF)

Figure S4 Effects of $5 \mu \mathrm{M}$ nifedipine on spontaneous $\mathbf{C a}^{2+}$ transients in hiPSG-CMs. Representative line scan (X$\mathrm{T}$ ) images (top) and the corresponding intensity profiles (bottom) of $\mathrm{Ca}^{2+}$ transients before and after the application ofnifedipine.

\section{References}

1. Bers DM (2002) Cardiac excitation-contraction coupling. Nature 415: 198-205.

2. Cheng H, Lederer WJ, Cannell MB (1993) Calcium sparks: elementary events underlying excitation-contraction coupling in heart muscle. Science 262: 740744.

3. Lopez-Lopez JR, Shacklock PS, Balke CW, Wier WG (1995) Local calcium transients triggered by single L-type calcium channel currents in cardiac cells. Science 268: 1042-1045.

4. Essin K, Gollasch M (2009) Role of ryanodine receptor subtypes in initiation and formation of calcium sparks in arterial smooth muscle: comparison with striated muscle. J Biomed Biotechnol 2009: 135249.

5. Zhu X, Altschafl BA, Hajjar RJ, Valdivia HH, Schmidt U (2005) Altered Ca ${ }^{2+}$ sparks and gating properties of ryanodine receptors in aging cardiomyocytes. Cell Calcium 37: 583-591.

6. Takahashi K, Tanabe K, Ohnuki M, Narita M, Ichisaka T, et al. (2007) Induction of pluripotent stem cells from adult human fibroblasts by defined factors. Cell 131: 861-872.

7. Lee YK, Ng KM, Lai WH, Chan YC, Lau YM, et al. (2011) Calcium Homeostasis in Human Induced Pluripotent Stem Cell-Derived Cardiomyocytes. Stem Cell Rev 7: 976-986.

8. Itzhaki I, Rapoport S, Huber I, Mizrahi I, Zwi-Dantsis L, et al. (2011) Calcium handling in human induced pluripotent stem cell derived cardiomyocytes. PLoS One 6: e18037.

9. Sauer H, Theben T, Hescheler J, Lindner M, Brandt MC, et al. (2001) Characteristics of calcium sparks in cardiomyocytes derived from embryonic stem cells. Am J Physiol Heart Circ Physiol 281: H411-421.

10. Xu XQ, Graichen R, Soo SY, Balakrishnan T, Rahmat SN, et al. (2008) Chemically defined medium supporting cardiomyocyte differentiation of human embryonic stem cells. Differentiation 76: 958-970.

11. Maltsev VA, Wobus AM, Rohwedel J, Bader M, Hescheler J (1994) Cardiomyocytes differentiated in vitro from embryonic stem cells developmentally express cardiac-specific genes and ionic currents. Circ Res 75: 233-244.

12. Guangqin Z, Yu F, Dongmei Y, Xuemei H, Shuhua B, et al. (2004) Contribution of spontaneous L-type $\mathrm{Ca}^{2+}$ channel activation to the genesis of $\mathrm{Ca}^{2+}$ sparks in resting cardiac myocytes. Sci China C Life Sci 47: 31-37.

13. Cheng H, Song LS, Shirokova N, Gonzalez A, Lakatta EG, et al. (1999) Amplitude distribution of calcium sparks in confocal images: theory and studies with an automatic detection method. Biophys J 76: 606-617.

14. Cheng H, Lederer MR, Lederer WJ, Cannell MB (1996) Calcium sparks and $\left[\mathrm{Ca}^{2+}\right]$; waves in cardiac myocytes. Am J Physiol 270: C148-159.

15. Yang Z, Pascarel C, Steele DS, Komukai K, Brette F, et al. (2002) $\mathrm{Na}^{+}-\mathrm{Ca}^{2+}$ exchange activity is localized in the T-tubules of rat ventricular myocytes. Circ Res 91: 315-322.

16. Sobie EA, Song LS, Lederer WJ (2005) Local recovery of $\mathrm{Ca}^{2+}$ release in rat ventricular myocytes. J Physiol 565: 441-447.

17. Huser J, Lipsius SL, Blatter LA (1996) Calcium gradients during excitationcontraction coupling in cat atrial myocytes. J Physiol 494 (Pt 3): 641-651. $\mathrm{n}_{\text {rat }}=5, \mathrm{n}_{\text {cell }}=13$. Abbreviations: $\mathrm{F} / \mathrm{F}_{0}$, fluorescence $(\mathrm{F})$ normalized to baseline fluorescence $\left(\mathrm{F}_{0}\right)$; s, seconds.

(TIFF)

Table S1 The percentages of hiPSG-CM subtypes and the action potential properties.

(DOCX)

Table S2 Spatio-temporal properties of $\mathrm{Ca}^{2+}$ sparks in rat cardiomyocytes.

(DOCX)

Table S3 Characteristics of spontaneous $\mathrm{Ca}^{2+}$ sparks in hiPSG-GMs derived from additional hiPSG lines derived from 3 healthy subjects.

(DOCX)

Text S1 Materials and Methods S1, Results S1, Discussion $\mathbf{S 1}$, References $\mathrm{S} 1$.

(DOCX)

\section{Author Contributions}

Conceived and designed the experiments: GQZ HW WS. Performed the experiments: GQZ JL HW. Analyzed the data: GQZ JL. Contributed reagents/materials/analysis tools: PW WS. Wrote the paper: GQZ HW WS.

18. Cordeiro JM, Spitzer KW, Giles WR, Ershler PE, Cannell MB, et al. (2001) Location of the initiation site of calcium transients and sparks in rabbit heart Purkinje cells. J Physiol 531: 301-314

19. Lohn M, Furstenau M, Sagach V, Elger M, Schulze W, et al. (2000) Ignition of calcium sparks in arterial and cardiac muscle through caveolae. Circ Res 87: 1034-1039.

20. Izu LT, Means SA, Shadid JN, Chen-Izu Y, Balke CW (2006) Interplay of ryanodine receptor distribution and calcium dynamics. Biophys J 91: 95-112.

21. Brette F, Orchard C (2003) T-tubule function in mammalian cardiac myocytes. Circ Res 92: 1182-1192.

22. Sheehan KA, Zima AV, Blatter LA (2006) Regional differences in spontaneous $\mathrm{Ca}^{2+}$ spark activity and regulation in cat atrial myocytes. J Physiol 572: 799-809.

23. Hescheler J, Fleischmann BK, Lentini S, Maltsev VA, Rohwedel J, et al. (1997) Embryonic stem cells: a model to study structural and functional properties in cardiomyogenesis. Cardiovasc Res 36: 149-162.

24. Kehat I, Kenyagin-Karsenti D, Snir M, Segev H, Amit M, et al. (2001) Human embryonic stem cells can differentiate into myocytes with structural and functional properties of cardiomyocytes. J Clin Invest 108: 407-414.

25. Baharvand H, Piryaei A, Rohani R, Taei A, Heidari MH, et al. (2006) Ultrastructural comparison of developing mouse embryonic stem cell- and in vivo-derived cardiomyocytes. Cell Biol Int 30: 800-807.

26. Baharvand H, Ashtiani SK, Valojerdi MR, Shahverdi A, Taee A, et al. (2004) Establishment and in vitro differentiation of a new embryonic stem cell line from human blastocyst. Differentiation 72: 224-229.

27. Satin J, Itzhaki I, Rapoport S, Schroder EA, Izu L, et al. (2008) Calcium handling in human embryonic stem cell-derived cardiomyocytes. Stem Cells 26: 1961-1972.

28. Blatter LA, Kockskamper J, Sheehan KA, Zima AV, Huser J, et al. (2003) Local calcium gradients during excitation-contraction coupling and alternans in atrial myocytes. J Physiol 546: 19-31.

29. Cheng H, Cannell MB, Lederer WJ (1995) Partial inhibition of $\mathrm{Ca}^{2+}$ current by methoxyverapamil (D600) reveals spatial nonuniformities in $\left[\mathrm{Ca}^{2+}\right]_{\mathrm{i}}$ during excitation-contraction coupling in cardiac myocytes. Circ Res 76: 236-241.

30. Cheng H, Lederer WJ (2008) Calcium sparks. Physiol Rev 88: 1491-1545.

31. Shiels HA, White E (2005) Temporal and spatial properties of cellular $\mathrm{Ca}^{2+}$ flux in trout ventricular myocytes. Am J Physiol Regul Integr Comp Physiol 288: R1756-1766.

32. Zhu WZ, Santana LF, Laflamme MA (2009) Local control of excitationcontraction coupling in human embryonic stem cell-derived cardiomyocytes. PLoS One 4: e5407.

33. Dolnikov K, Shilkrut M, Zeevi-Levin N, Gerecht-Nir S, Amit M, et al. (2006) Functional properties of human embryonic̀stem cell-derived cardiomyocytes: intracellular $\mathrm{Ca}^{2+}$ handling and the role of sarcoplasmic reticulum in the contraction. Stem Cells 24: 236-245.

34. Sartiani L, Bettiol E, Stillitano F, Mugelli A, Cerbai E, et al (2007) Developmental changes in cardiomyocytes differentiated from human embryonic stem cells: a molecular and electrophysiological approach. Stem Cells 25: 1136-1144. 